\title{
ASSOCIATION OF SIT-TO-STAND PATTERN WITH FUNCTIONAL MOBILITY IN STROKE PATIENTS AND ELDERLY POPULATION
}

\section{Urooj Rafi $^{\otimes I}$, Saira Jahan ${ }^{2}$, Arshad Nawaz Malik ${ }^{3}$}

\begin{abstract}
OBJECTIVE: To compare sit-to-stand (STS) pattern and different functional mobility tests in stroke and elderly population.

METHODS: This cross-sectional study was carried at Physical therapy departments of Pakistan Railway Hospital Rawalpindi, Rafsan Neuro Rehabilitation Centre Peshawar and DOW Medical Hospital Karachi, Pakistan. Study duration was 6 months from June 2016 to November 2016 with a sample size of 100. Non-Probability purposive sampling technique was adopted for sample collection. After informed consent, data including demographics details and results of applied tests were recorded and analyzed through SPSS version21. Independent sample T-test was used to measure difference among means, while Odds Ratio was calculated to measure the association.
\end{abstract}

RESULTS: The mean age of stroke patients was $54.5 \pm 9.83$ years and mean age of elder population was $65.3 \pm 9.44$ years. The association of STS pattern and different functional mobility between stroke patients and elderly population showed higher odds for each step of elderly population with an OR of 42.667, $2.667, \mathrm{I} .826$, I.556 and I .690 for feet behind knees, pre-extension, extension, knee extension and hip extension respectively. The mean scores of five times sit-to-stand test in stroke population group was $33.8 \pm 8.59 \mathrm{sec}$ and $18.4 \pm 8.59$ sec in elder population $(p<0.05)$. Mean scores of timed up and go test, Tinneti performance oriented mobility scale, Berg Balance Scale \& Mini-Best test showed a significant difference among these tests $(p<0.05)$.

CONCLUSION: Elderly population can perform STS pattern with much ease as compared to stroke patients while the different functional mobility tests have a significant difference among its values.

KEY WORDS: Stroke (MeSH); Elderly (MeSH); Sit-to-stand (Non-MeSH); Mobility Tests (Non-MeSH) Timed up and go test (Non-MeSH); Tinneti performance oriented mobility scale (Non-MeSH); Berg Balance scale (Non$\mathrm{MeSH})$; Mini-Best test (Non-MeSH).

THIS ARTICLE MAY BE CITED AS: Rafi U, Jahan S, Malik AN. Association of sit-to-stand pattern with functional mobility in stroke patients and elderly population. Khyber Med Univ J 2019;1I(2):75-8. DOI: 10.35845/kmuj.2019.18499

\section{INTRODUCTION}

S roke is a vascular impairment of the blood flow to the brain that causes neurological dysfunction due to abnormal cerebral circulation. Patient's disability or weakness depends upon the corresponding damaged area of the brain.' Globally, stroke burden is high, with increase incidence and mortality rate particularly in middle and low income countries. ${ }^{2}$ Stroke is known to be the second leading cause of death; i.e. 4.4 millions of total deaths each year worldwide today and in United States I 29000 people die per year. ${ }^{3}$ The frequency of large vessel intracranial atherosclerotic disease (ICAD) is high among Asians that cause $30 \%$ to $50 \%$ of stroke among south Asian population. James Mclntosh in January 2016,
I. Pakistan Railway General Hospital, Rawalpindi, Pakistan

2. Islamic International Medical College, Riphah International University, Islamabad, Pakistan

Emailه: jdrsyri@yahoo.com Contact \#: $\quad$ +92-3415182331

3. Riphah International University, Islamabad, Pakistan

$\begin{array}{ll}\text { Date Submitted: } & \text { July 10, } 2018 \\ \text { Date Revised: } & \text { May 08, 2019 } \\ \text { Date Accepted: } & \text { May 09, 2019 }\end{array}$

suggested in his study that stroke is the fourth leading cause of death in United States and the death of a single person in every 4 minutes. ${ }^{5}$ Pakistan is the sixth most populous country in the world, the incidence rate of stroke in Pakistan is $250 / 100,000$ or 350,000 new cases per year. ${ }^{6}$ According to another study prevalence of stroke is $4.8 \%$ in single ethnic group in Pakistan. ${ }^{7}$

The most common symptom after stroke is weakness on the affected side, which is caused by an imbalance in muscle strength; as a result, patients with hemiplegia have asymmetric weight bearing on one side, which exacerbates their balance problems. Difficulties in controlling balance can lead to numerous problems in activities of daily living. ${ }^{8}$

Sit-to-stand (STS) is very simple task for normal healthy individual but it is an important precursor towards functional mobility. In stroke and elder population, many movements can be seen beyond normal biomechanics. 'According to the literature, STS is the complex task in which postural control is required to change three-point-based siting to twopoint-based standing posture. ${ }^{10}$ In STS, power flows greater at hip than knees, but compressive forces at knee are slightly greater in sitting down than standing up. The angular velocity at knee decreased in sitting down. A recent review of 39 STS studies concluded that chair height, armrest and foot positioning considerably influence STS activity."

STS activity is very important that is used in the clinical assessments and is the major factor to determine the level of independence in elderly and disabled 
TABLE I: SIT-TO-STAND PATTERN IN STROKE PATIENTS AND ELDERLY POPULATION

\begin{tabular}{|l|c|c|c|c|c|c|}
\hline \multirow{2}{*}{ STS PATTERN } & \multicolumn{3}{|c|}{ STROKE PATIENTS } & \multicolumn{3}{c|}{ ELDERLY POPULATION } \\
\cline { 2 - 7 } & YES & NO & OR & YES & NO & OR \\
\hline Feet behind knees & 18 & 32 & 0.23 & 48 & 2 & 42.667 \\
\hline Pre-extension & 30 & 20 & 0.37 & 40 & 10 & 2.667 \\
\hline Extension & 12 & 38 & 0.548 & 17 & 33 & 1.826 \\
\hline Knee extension & 15 & 35 & 0.643 & 20 & 30 & 1.556 \\
\hline Hip extension & 15 & 35 & 0.592 & 21 & 29 & 1.690 \\
\hline
\end{tabular}

$\mathrm{OR}=$ Odds Ratio

TABLE II: FUNCTIONAL MOBILITY TESTS IN STROKE PATIENTS AND ELDER POPULATION

\begin{tabular}{|c|c|c|c|c|c|}
\hline \multirow{2}{*}{$\begin{array}{l}\text { Functional Mobility } \\
\text { Tests }\end{array}$} & \multicolumn{2}{|c|}{ Stroke Patients } & \multicolumn{2}{|c|}{ Elderly Population } & \multirow{2}{*}{$\begin{array}{c}\text { p-value } \\
\text { (independent } \\
\text { sample t-test) }\end{array}$} \\
\hline & $\begin{array}{c}\text { Mean } \\
\text { (seconds) }\end{array}$ & SD & $\begin{array}{c}\text { Mean } \\
\text { (seconds) }\end{array}$ & SD & \\
\hline $\begin{array}{l}\text { Five times sit-to-stand } \\
\text { test }\end{array}$ & 33.8 & 8.59 & 18.4 & 8.59 & $<0.05$ \\
\hline Timed up and go test & 49.91 & 21.38 & 26.61 & 12.43 & $<0.05$ \\
\hline Berg balance Test & 32.14 & 10.01 & 47.98 & 5.59 & $<0.05$ \\
\hline $\begin{array}{l}\text { Tinneti performance } \\
\text { oriented mobility scale }\end{array}$ & 13.24 & 5.12 & 24.24 & 2.74 & $<0.05$ \\
\hline Mini-Best test & 9.7 & 3.73 & 17.62 & 5.84 & $<0.05$ \\
\hline
\end{tabular}

population. In a study it was suggested that elder individuals takes longer average time with anterior head displacement in those using armrest compared with those rising without armrest from the chair." In patients and elderly people STS activity can used as health maker that improve balance and strength to be independent in activities of daily living (ADLs). ${ }^{10}$

Sit-to-stand transfer is an essential task towards functional mobility and this becomes affected by aging and other pathology that may cause disability. Repeated task of STS is the main component of exercise plan for the elderly adults. Those elderly adults who perform inadequate amount of STS activity per day might experience decreased strength impairment and work deficit. ${ }^{2}$ In an attempt to determine the association of sit-tostand with functional mobility we conducted a co-relational study to determine the association of sit-tostand and functional mobility in stroke patients and elder population.

\section{METHODS}

This co-relational cross sectional study was carried out with the approval of tabulation Odds Ratio was calculated for STS pattern among Stroke patients and elderly population. Data was analyzed through SPSS 21.0.

\section{RESULTS}

The total number of patients in this study was 100 , out of which 50 were stroke patients and 50 were elderly adults. The mean age of stroke patients was $54.5 \pm 9.83$ years while the mean age of elder population was $65.3 \pm 9.44$ years. Out of 50 stroke patients 40 were males and 10 were females that shows the rate of stroke was higher in males than in females.

The association of STS pattern and different functional mobility between stroke patients and elderly population showed higher odd for each step of elderly population with an OR of 42.667, 2.667, I.826, I.556 and I.690 for feet behind knees, pre-extension, extension, knee extension and hip extension respectively (Table I).

The mean scores of Five times sit-tostand test in stroke population group was $33.8 \pm 8.59 \mathrm{sec}$ and $18.4 \pm 8.59 \mathrm{sec}$ in elder population (Table II). Mean scores of FTSTS, TUG, BBS, POMA and Mini-Best test showed a significant difference among these tests $(p<0.05)$.

\section{DISCUSSION}

In our study, STS pattern and different functional mobility between stroke patients and elderly population showed higher odd for each step of elderly population for feet behind knees, preextension, extension, knee extension and hip extension as compared to stroke patients.

The mean age of stroke population was $54.5 \pm 9.83$ years in this study; nearly similar mean age has been shown in another study evaluating stroke patients. ${ }^{16}$ In our study the extension phase was not present properly in 38\% of stroke patients and $33 \%$ of elderly adults while in other study the risk of fall was greater and need more time for stabilization especially during extension phase of sit-to-stand activity.' In this study, full-knee-extension was not present in $35 \%$ of stroke patients and $30 \%$ of elderly adults comparing with 
another research sample with chronic stroke knee extensor weakness which takes greater time to rise during sit-tostand activity than normal individual (elderly). ${ }^{17}$

According to the results of this study, there were lateral deviations of trunk towards unaffected side in 44 stroke patients out 50. Many studies supports our study in literature i.e. most of the hemiperitic individuals who are able to perform sit-to-stand activity independently have lateral deviation of trunk towards unaffected side due to which asymmetrical weight bearing takes place. ${ }^{9}$ According to another study patients with hemiparesis, were able to stand independently and show several changes beyond normal i.e. trunk lateral deviation towards unaffected side with asymmetrical weight bearing and knee moment forces. Asymmetrical weight bearing was seen before seat off and the involved side remains still in contact with chair. ${ }^{17}$ Postural sway would increase due to balance impairment during sit-to-stand activity. On the other hand, in our study the extension phase was not present properly in $38 \%$ of stroke patients and $33 \%$ of older adults; in other study the risk of fall was greater and needed more time for stabilization especially during extension phase of sitto-stand activity. ${ }^{17}$

In stroke population, the time to STS activity and other ADLs is greater than the normal elderly individuals due to hemiparesis and muscle weakness; in our study, we correlate STS activity within elderly adults and stroke population. The time of STS task in FTSTS and TUG test was greater than the normal; the scores of POMA, BBS and Mini Best test was lesser than that which showed greater risk of fall with decreased functional mobility. The mean and standard deviation of fivetime sit-to-stand test in stroke population group is $33.8 \pm 8.59 \mathrm{sec}$ and $18.4 \pm 8.59 \mathrm{sec}$ in elder population group with $\mathrm{p}$-value is $0.000(<0.05)$ which is significant. In 20I4, many other studies shows nearly same means of five times sit-to-stand test times i.e. 15.2 to I7. I seconds for six different conditions in five times sit-to-stand test. ${ }^{18}$

In this study, there were significant difference in the mean scores FTSTS test and TUG in both groups. Goldberg $A$, et al confirmed the validity of FTSTS as a measure of dynamic balance and functional mobility in older adult. ${ }^{19}$ The mean TUG test in stroke population was $49.91 \pm 21.38 \mathrm{sec}$ while in elder population group was $26.6 \mathrm{I} \pm 12.43 \mathrm{sec}$ which shows the greater fall risk. BBS score had the mean value of $32.14 \pm 10.01$ seconds in stroke and $47.98 \pm 5.59$ seconds in elder population respectively. Azad A, et al. ${ }^{20}$ in a study found mean of BBS was $48.05 \pm 8.77$ seconds and mean of TUG is $22.8 \pm 21.76$ seconds. TUG test was indicated to measure for stroke patients who are more prone to have fall risk. ${ }^{20}$

Downs S, et al. ${ }^{21}$ did a search from 17 relevant studies and suggests that the mean BBS score of 1363 individuals ranged from $37 \pm 1.0$ to $55 \pm 9.2$ in normal elderly adults around 70 years of age, showing a significant decline in balance with age. ${ }^{21}$ In our study BBS score showed the increased risk of fall in stroke patients than the normal elderly population.

A cross-sectional survey in 2010-2012 also suggests that there were poor performance of STS and TUG in elderly people of age 65 to 86 years. In our study, higher values of FTSTS and TUG test suggested an increased risk of fall and decline in functional mobility. ${ }^{22}$

This was a small-scale study and there is a need of large-scale study over a long period, including electromyography studies to measure muscle performance during STS activity. The study can be done to increase awareness in elderly adults and stroke patients in Pakistan for better results in the community.

\section{CONCLUSION}

The study concludes that elderly population has much ease in performing STS pattern activities as compared to stroke population. The means of different functional mobility tests showed a significant difference among the values. Hence, it can be extracted that stroke affects the mobility of a person more than ageing and can increased various mobility related complications.

\section{REFERENCES}

I. Schmitz TJ, O'Sullivan SB. Examination of coordination and balance. Chap 6. In: O'Sullivan SB, Schmitz TJ, Fulk G. Physical Rehabilitation. $6^{\text {th }}$ Ed. Philadelphia. F.A.Davis. 2013:206.

2. Mukherjee D, Patil CG . Epidemiology and the global burden of stroke. World Neurosurg $20 \mathrm{II} ; 76$ (6Suppl) : S8 5 - 90 . DOI:10.1016/j.wneu.2011.07.023.

3. Mozaffarian D, Benjamin EJ, Go AS, Arnett DK, Blaha MJ, Cushman M, et al. Heart disease and stroke statistics-20 I 6 update a report from the American Heart Association. Circulation 2016;133(4):e38-360. DOI: I0.1I6I/CIR.0000000000 000350.

4. Kamal AK, Rehman $\mathrm{H}$, Mustafa N, Ahmed B, Jan M, Wadivalla F, et al. Diagnostic TCD for intracranial stenosis in acute stroke patients: experience from a tertiary care stroke center in Karachi, Pakistan. BMC Res Notes 2015;8:34I. DOI: |0.||86/s|3|04-0|5-|289-3.

5. Falcon MI, Riley JD, Jirsa V, McIntosh $A R$, Shereen $A D$, Chen EE, et al. The virtual brain: modeling biological correlates of recovery after chronic stroke. Front Neurol 20।5;6:228. DOI: I0.3389/ fneur.2015.00228.

6. Wasay M, Jabbar A. Fight against chronic diseases (high blood pressure, stroke, diabetes and cancer) in Pakistan; cost-effective interventions. J Pak Med Assoc 2009;59(4): 196-7.

7. Khan M, Kamal AK, Pasha O, Islam M, Azam I, Virk A, et al. Study Protocol: Validation and Adaptation of community-workeradministered stroke symptom questionnaire in a periurban Pakistani community to determine disease burden. J Vasc Interv Neurol 20I5;8(I):I-I0.

8. Park JH, Kim YM, Lee NK. The effects of repetitive sit-to-stand training with a paretic-side asymmetrical foot position on the balance of chronic stroke subjects. J 
Korean Phys Ther 2015;27(3): 16973. DOI:I0.18857/jkpt.20I5. 27.3.169.

9. Boukadida A, Piotte F, Dehail P, Nadeau S. Determinants of sit-tostand tasks in individuals with hemiparesis post stroke: a review. Ann Phys Rehabil Med 20I5;58(3):167-72. DOI: 10.1016/ j.rehab.2015.04.007

10. Cho S, Byeon H. Muscle activity of lower extremities for normal adults according to the type of chair and posture during sit-to-stand movement. Int J Biosci Biotech 20I5;7(3):5I-60. DOI: 10.14257 /ijbsbt.2015.7.3.06.

II. Etnyre B, Thomas DQ. Event standardization of sit-to-stand movements. Phys Ther 2007;87(| 2):|65|-66. DOI: 10. 2522/ptj.20060378.

12. Bohannon RW. Daily sit-to-stands performed by adults: a systematic review. J Phys Ther Sci 20।5;27(3):939-42. DOI: I0.1589/jpts.27.939.

13. Mong Y, Teo TW, Ng SS. 5-repetition sit-to-stand test in subjects with chronic stroke: reliability and validity. Arch Phys Med Rehabil 2010;91(3):407-I3. DOI: 10. 1016/j.apmr.2009.10.030.

14. Dowarah BP, Ghosh S. A
Comparative Study of Timed Up and Go Test and Tinetti Performance Oriented Mobility Assessment in Predicting Falls in Hemiparetic Stroke Patients. Research \& Reviews: J Neurosci 2014;4(3): 14-8.

15. Chinsongkram B, Chaikeeree $\mathrm{N}$, Saengsirisuwan V, Horak FB, Boonsinsukh R. Responsiveness of the Balance Evaluation Systems Test (BESTest) in people with subacute stroke. Phys Ther 2016;96(10): 1638-47. DOI:I0.2522/ptj. 20150621 .

16. Silva PF, Quintino LF, Franco J, Faria CD. Measurement properties and feasibility of clinical tests to assess sit-to-stand/stand-to-sit tasks in subjects with neurological disease: a systematic review. Braz J Phys Ther 2014; I8(2):99-II0. DOI: 10.1590/ SI4I3-355520I2005000I55.

17. Ng SS, Cheung SY, Lai LS, Liu AS, leong $\mathrm{SH}$, Fong SS. Association of seat height and arm position on the five times sit-to-stand test times of stroke survivors. Biomed Res Int. 20I3;20I3: 642362. DOI: $10.1155 / 2013 / 642362$.

18. Kwong PW, Ng SS, Chung RC, Ng GY. Foot placement and arm position affect the five times sit-tostand test time of individuals with chronic stroke. Biomed Res Int
$2014 ; 20 \mid 4: 636530$. DOI: I0.1|55/20|4/636530.

19. Goldberg A, Chavis M, Watkins J, Wilson T. The five-times-sit-tostand test: validity, reliability and detectable change in Elderly females. Aging Clin Exp Res 20I2;24(4):339-44. DOI: I0.1007/ BF03325265.

20. Azad A, Mehraban AH, Mehrpour $M$, Mohammadi B. Clinical assessment of fear of falling after stroke: validity, reliability and responsiveness of the Persian version of the Fall Efficacy ScaleInternational. Med J Islam Repub Iran $2014 ; 28: 131$.

21. Downs S, Marquez J, Chiarelli P. Normative scores on the Berg Balance Scale decline after age 70 years in healthy communitydwelling people: a systematic review. J Physiother 20। 4;60(2):859. DOI: $10.10 \mathrm{I} 6 / \mathrm{j} . j p h y s$. 20।4.01.002. Epub 20 I 4 Jun I3.

22. Soma Y, Tsunoda K, Kitano N, Jindo T, Tsuji T, Saghazadeh $M$, et al. Relationship between built environment attributes and physical function in Japanese community dwelling elderly adults. Geriatr Gerontol Int 2017;17(3):382-90. DOI: 10.1 I I I/ggi. I 2717 .

\section{AUTHORS' CONTRIBUTIONS}

Following authors have made substantial contributions to the manuscript as under:

UR: Conception, acquisition of data, drafting the manuscript, final approval of the version to be published

SJ: Data analysis \& interpretation, drafting the manuscript, final approval of the version to be published

ANM: Concept \& study design, analysis and interpretation of data, critical revision, final approval of the version to be published

Authors agree to be accountable for all aspects of the work in ensuring that questions related to the accuracy or integrity ofany part of the work are appropriately investigated and resolved.

CONFLICT OF INTEREST
Authors declared no conflict of interest
GRANT SUPPORT AND FINANCIAL DISCLOSURE
NIL

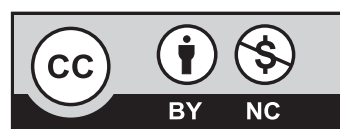

This is an Open Access article distributed under the terms of the Creative Commons Attribution-Non Commercial 2.0 Generic License. 